\title{
CFD Analysis of Thermal Comfort in Hospital Operation Room with Different Air Distribution Design and Operative Temperature
}

MZM Samidi', H Husain ${ }^{1, *}$ and MS Meon ${ }^{1}$

${ }^{1}$ School of Mechanical Engineering, College of Engineering, Universiti Teknologi MARA, Shah Alam 40450 Selangor, Malaysia.

"corresponding author: hazran@uitm.edu.my

\section{ABSTRACT}

The operation room is one of the most critical regions in hospital that require extra attention of air ventilation and prevention of dangerous pollutants contamination. A good level of ventilation will help to raise the productivity of workers in terms of performance and ensuring a safe surgery operation. It is obvious that today's operation rooms are completely equipped with mechanical ventilation systems. However, despite the fact that they meet the acceptable comfort standards, surgical workers have complained about thermal discomfort during operation which gives negative impact on their performance. Thermal comfort can be achieved by controlling the temperature, relative humidity and air movement. In this study, the operation room models were simulated to analyse the comfort conditions of surgical workers under 3 different air velocities of $0.2 \mathrm{~ms}^{-1}, 0.25 \mathrm{~ms}^{-1}$ and $0.35 \mathrm{~ms}^{-1}$, and under 5 different temperatures of $16^{\circ} \mathrm{C}$ to $20^{\circ} \mathrm{C}$. Additionally, there were two 3D models created with different position of exhaust vent. The thermal comfort of surgical workers was measured using Predicted Mean Vote (PMV) and Predicted Percentage Dissatisfied (PPD) approaches through CBE Thermal Comfort Tool. The PMV and PPD results showed that most surgical workers were outside the acceptable range value of -0.5 to +0.5 as stated in ASHRAE Standard 55-2020. According to thermal scale index, most of the surgical workers were in a cool and slightly cool state despite the fact that computational analysis showed an acceptable simulation validated with previous research studies. Finally, it was discovered that clothing insulation, metabolic rate, mechanical equipment and air distribution design played a significant influence in providing comfort to the surgical workers.

Keywords: thermal comfort, operation room, $P M V, P P D, C F D$

Nomenclature (Greek symbols towards the end)

$\begin{array}{cl}w / m^{2} & \text { Watt per Metre Square } \\ \mathrm{m} / \mathrm{s} & \text { Metre per Second } \\ \mathrm{met} & \text { Metabolic Rate Ratio } \\ P & \text { Static Pressure } \\ \mu & \text { Dynamic Viscosity of a Fluid } \\ \rho g_{x}, \rho g_{y}, \rho g_{z} & \text { Body Forces in the } \mathrm{x}, \mathrm{y} \text { and } \mathrm{z} \text { Directions } \\ \lambda & \text { Thermal Conductivity } \\ C_{p} & \text { Specific Heat } \\ \rho & \text { Density } \\ u, v, w & \text { Components of Velocity } \\ \mathrm{x}, \mathrm{y}, \mathrm{z} & \text { Direction of Velocity } \\ T & \text { Temperature } \\ \alpha & \text { Thermal Diffusivity } \\ P_{r} & \text { Prandtl Number }\end{array}$

\section{Abbreviations}

Air Changes per Hour

ASHRAE

CBE

American Society of Heating, Refrigerating and Air-Conditioning Engineer

CFD

Centre for the Built Environment

FYP

Computational Fluid Dynamics

HEPA

Final Year Project

HVAC

IAQ

High Efficiency Particulate Air

ISO

Heating, Ventilating and Air-Conditioning

Indoor Air Quality

LAF

International Organization for Standardization

Laminar Airflow 


$\begin{array}{ll}\text { NSE } & \text { Navier-Stokes Equation } \\ \text { OR } & \text { Operation Room } \\ \text { PMV } & \text { Predicted Mean Vote } \\ \text { PPD } & \text { Predicted Percentage Dissatisfied } \\ \text { RH } & \text { Relative Humidity } \\ \text { TAF } & \text { Turbulent Airflow }\end{array}$

\subsection{INTRODUCTION}

Hospitals always require special attention in terms of HVAC system design and operation, which include hygiene, air movement and airborne transmissions control. According to a researcher, patients who are treated in regulated setting surroundings would recuperate quicker than those who are treated in an unregulated environment [1]. In the past few decades, a lot of research was conducted to improve the efficiency of surgical sites. Despite the diligent hard work, infection rate is still rising. This contamination is known as Surgical Site Infection (SSI). Researchers have discovered that various factors such as patient variables, room variables, surgical variables and the effectiveness of HVAC installation variables contribute to the impact of harmful bacteria presence in operation room $(\mathrm{OR})[2]$.

The acknowledgement of these factors has resulted in the need for high-level ventilation systems which can reduce the existence of pathogens and improve the thermal comfort. It can also elevate the productivity, safety and health of the surgical workers and patient during surgery. In thermal comfort field, there are two international standards used which are ISO 7730 and ASHRAE 55. These standards work as a guideline in developing efficient ventilation system in hospital facilities as well as ensuring thermal satisfaction towards the occupants. Besides that, the factors that influence the evaluation of thermal comfort are individual (clothing insulation, metabolic rate) and environmental (air temperature, mean radiant temperature, humidity, air velocity) factors as studied by Angelova and Velichkova [3]. In other words, they are known as human thermal balance. The parameters of these factors can be gathered in delivering a desired thermal comfort condition.

Most of the operation rooms across the globe are designed based on these standard comfort criteria which are believed to have the advantage in providing thermal comfort environment. However, these criteria ring a warning bell when the dependability of executing these criteria contributes to the thermal discomfort experienced by the surgical workers. This thermal discomfort is believed to be affecting their work performance and contribute to a perception that additional design consideration must be taken into account while using these standards. Hence, the necessity of conducting analysis at the design stage is vital in order to achieve an acceptable thermal comfort level.

\subsection{METHODOLOGY}

\subsection{Theoretical calculation}

Thermal comfort is a subjective state of mind that is used to evaluate occupant satisfaction with the thermal environment. It is mandatory to install an adequate ventilation system in the OR since it gives a high degree of thermal satisfaction for surgical workers, and increase their productivity and quality of work. In other words, thermal comfort may be described as a heat transfer phenomenon that can be analysed using the fluid motion mechanism. Prior to the physical essential properties of fluids, this study employed a CFD approach which included the study of fluids in motion via computational solution [4]. Theoretically, fluid flow regimes are classified as laminar, transitional or turbulent. Despite the fact that they produce distinct formulas at the end of their derivation based on their properties, each of these regimes is fundamentally governed by the same NSE conservation principles.

This study utilized a LAF model to analyse the thermal comfort of surgical workers, implying that there was no influence of velocity fluctuation contrasted to TAF model where the velocity fluctuation was critical. Additionally, the LAF model generated a low Reynolds number which allowed the fluid to move smoothly with no interruption inside the paths. The use of CFD software in this study was based on three basic conservation laws of physics which were mass, momentum and energy conservations. This software adequately predicts the flow of fluids, heat transfer and related phenomena in the fluid region of interest by numerically solving the mathematical equations [5-6]. The final derivation of conservation principle equations is described below and the factors influencing the equations must be balanced. 
Where,

$$
\frac{\partial \rho}{\partial t}+\frac{\partial}{\partial x}(\rho u)+\frac{\partial}{\partial y}(\rho v)+\frac{\partial}{\partial z}(\rho w)=0
$$

$$
\begin{aligned}
& \rho=\text { density } \\
& u, v, w=\text { components of velocity } \\
& \mathrm{x}, \mathrm{y}, \mathrm{z}=\text { direction of velocity }
\end{aligned}
$$

Equation (1) illustrates the partial differential form of continuity equation for conservation of mass which indicates that the rate of change of mass within the control volume is equivalent to the mass flux crossing the volume surface. In order to perform simulation, this equation requires relevant inputs such as boundary conditions and initial parameters.

$$
\begin{gathered}
\text { Conservation of momentum } \\
\text { For x-direction (U-momentum) } \\
\rho\left(\frac{\partial u}{\partial t}+u \frac{\partial u}{\partial x}+v \frac{\partial u}{\partial y}+w \frac{\partial u}{\partial z}\right)= \\
-\frac{\partial P}{\partial x}+\frac{\partial}{\partial x}\left[2 \mu \frac{\partial U}{\partial x}-\frac{2}{3} \mu\left(\frac{\partial u}{\partial x}+\frac{\partial v}{\partial y}+\frac{\partial w}{\partial z}\right)\right]+\frac{\partial}{\partial y}\left[\mu\left(\frac{\partial u}{\partial y}+\frac{\partial v}{\partial x}\right)\right]+\frac{\partial}{\partial z}\left[\mu\left(\frac{\partial u}{\partial z}+\frac{\partial w}{\partial x}\right)\right]+\rho g_{x} \\
\text { For y-direction (V-momentum) } \\
\rho\left(\frac{\partial v}{\partial t}+u \frac{\partial v}{\partial x}+v \frac{\partial v}{\partial y}+w \frac{\partial v}{\partial z}\right)= \\
\left.\frac{\partial}{\partial y}+\frac{\partial}{\partial x}\left[\mu\left(\frac{\partial v}{\partial x}+\frac{\partial u}{\partial y}\right)\right]+\frac{\partial v}{\partial y}-\frac{2}{3} \mu\left(\frac{\partial u}{\partial x}+\frac{\partial v}{\partial y}+\frac{\partial w}{\partial z}\right)\right]+\frac{\partial}{\partial z}\left[\mu\left(\frac{\partial v}{\partial z}+\frac{\partial w}{\partial y}\right)\right]+\rho g_{y}
\end{gathered}
$$

For z-direction (W-momentum)

$$
\begin{gathered}
\rho\left(\frac{\partial w}{\partial t}+u \frac{\partial w}{\partial x}+v \frac{\partial w}{\partial y}+w \frac{\partial w}{\partial z}\right)= \\
-\frac{\partial P}{\partial z}+\frac{\partial}{\partial x}\left[\mu\left(\frac{\partial w}{\partial x}+\frac{\partial u}{\partial z}\right)\right]+\frac{\partial}{\partial y}\left[\mu\left(\frac{\partial w}{\partial y}+\frac{\partial v}{\partial z}\right)\right]+\frac{\partial}{\partial z}\left[2 \mu \frac{\partial w}{\partial z}-\frac{2}{3} \mu\left(\frac{\partial u}{\partial x}+\frac{\partial v}{\partial y}+\frac{\partial w}{\partial z}\right)\right]+\rho g_{z}
\end{gathered}
$$

Where for equation (2) to (4),

$P=$ static pressure

$\mu=$ dynamic viscosity of a fluid

$\rho=$ density

$\rho g_{x}, \rho g_{y}, \rho g_{z}=$ body forces in the $\mathrm{x}, \mathrm{y}$ and $\mathrm{z}$ directions

$u, v, w=$ components of velocity

$\mathrm{x}, \mathrm{y}, \mathrm{z}=$ direction of velocity

$$
\frac{\partial T}{\partial t}+u \frac{\partial T}{\partial x}+v \frac{\partial T}{\partial y}+w \frac{\partial T}{\partial z}=\frac{\lambda}{\rho C_{p}} \frac{\partial^{2} T}{\partial x^{2}}+\frac{\lambda}{\rho C_{p}} \frac{\partial^{2} T}{\partial y^{2}}+\frac{\lambda}{\rho C_{p}} \frac{\partial^{2} T}{\partial z^{2}}
$$

Where

$$
\begin{aligned}
& \lambda=\text { thermal conductivity } \\
& \rho=\text { density } \\
& C_{p}=\text { specific heat } \\
& T=\text { temperature } \\
& \frac{\lambda}{\rho C_{p}}=\alpha=\text { thermal diffusivity } \\
& P_{r}=\frac{\mu C_{p}}{\lambda}=\text { Prandtl number }
\end{aligned}
$$

Lastly, these equations are solved using airflow modelling which entails superimposing a grid with hundreds of thousands of cells representing physical characteristics, air and temperature inputs. In particular, those equations are solved simultaneously in a repetition form and turned into algebraic equations that satisfy the conservation principles concept. This is known as discretization and it entails splitting the operating region into 
thousands of cells. As a result, the fluid flow can be observed in any part of the space as depicted in the analysis result section where the contours on the OR study plan is visible.

\subsection{Numerical modelling}

The 3D models portraying the OR design were designed using ANSYS Fluent software as demonstrated in Figs. 1 and 2. It is observed through the figures that the exhaust vent was located at a low level (Design 1) and high level (Design 2). These models were constructed identically in terms of their dimension which was $6 \mathrm{~m} \mathrm{~L} \mathrm{x}$ $7 \mathrm{~m} \mathrm{~W} \times 3 \mathrm{~m} \mathrm{H}$. It is essential to choose adequate air diffusers that supply a downward and unidirectional airflow which covers most of the area in surgical site. ASHRAE Standard 55 [7] recommends air diffuser which is greater than $0.3 \mathrm{~m}$ in dimension when compared to the operation table. The dimension of operation table was $1.8 \mathrm{~m} \mathrm{Lx}$ $0.8 \mathrm{~m} \mathrm{~W} \times 0.8 \mathrm{~m} \mathrm{H}$ while the air diffuser was measured as $2.6 \mathrm{~m} \mathrm{~L} \times 2.4 \mathrm{~m} \mathrm{~W} \times 0.3 \mathrm{~m} \mathrm{H}$. The air diffuser was located at the center of the OR. Meanwhile, air in the operation room was removed through 6 exhaust vents with identical dimensions of $0.9 \mathrm{~m} \mathrm{~L} \times 0.4 \mathrm{~m} \mathrm{H} \times 0.2 \mathrm{~m} \mathrm{~W}$ that were positioned against two opposite-facing sidewalls at the OR low level (Design 1) and high level (Design 2). The dimension of the inlet and outlet in this present study was selected from previous study performed by C. Liu et al. [8].

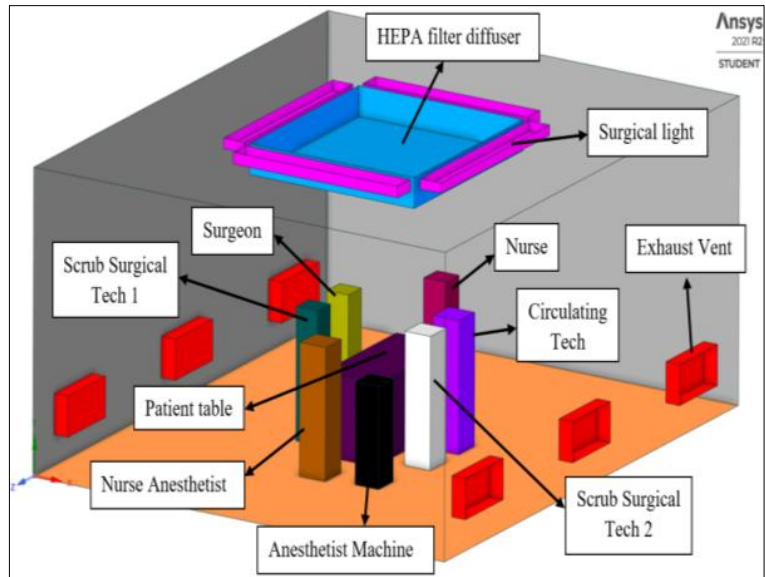

Figure 1: Operation room Design 1

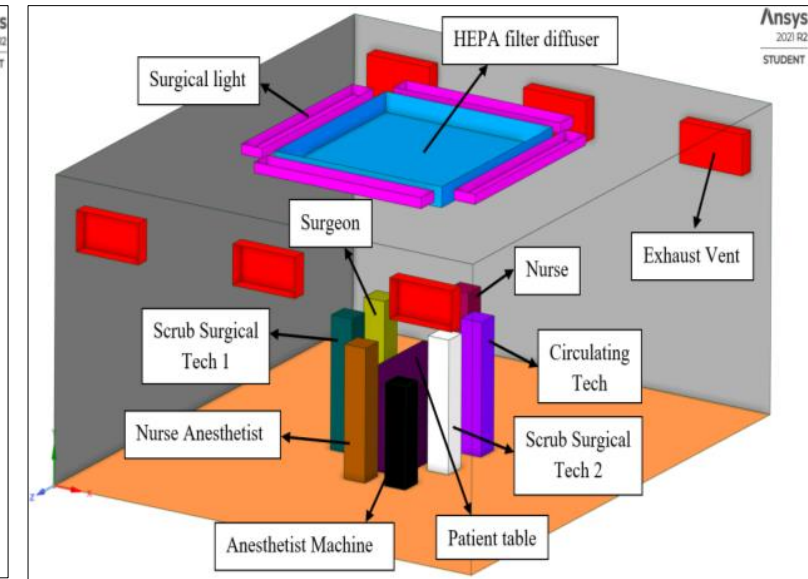

Figure 2: Operation room Design 2

Additionally, there were 6 surgical workers standing around the operation table beneath 4 surgical lights. The surgical workers were surgeon, nurse anaesthetist, circulating tech, nurse, scrub surgical tech 1 and 2 . The anaesthetist machine was located at the edge of the operation table, next to the nurse anaesthetist and scrub tech 2. It was essential to develop a model of human body because it gave an impact on the assessment of thermal comfort. According to previous studies [9-10], the average human skin temperature is about $33.7^{\circ} \mathrm{C}$. The simplified block-shape was employed as the human structure that depicted the surgical workers. The use of simplified human block tends to overlook the convective heat transmission by $20 \%$ in a range of speed less than $0.4 \mathrm{~m} / \mathrm{s}$ [10-11]. However, it was acceptable to use simplified human block since the major focus of this study examined the thermal comfort level. The dimension of the human block is listed in Table 1.

Table 1: Measurement of surgical staffs extracted from ANSYS GEOMETRY

\begin{tabular}{ccccc}
\hline Surgical Workers & Length & $\begin{array}{c}\text { Dimensions }(\mathbf{m}) \\
\text { Width }\end{array}$ & Height & Area $\left(\mathbf{m}^{\mathbf{2}}\right)$ \\
\hline $\begin{array}{c}\text { Surgeon } \\
\text { Scrub Surgical Tech 1 }\end{array}$ & 0.31 & 0.31 & 1.3 & 1.696 \\
Nurse Anaesthetist & 0.38 & 0.38 & 1.3 & 2.097 \\
$\quad$ Circulating Tech & 0.37 & 0.37 & 1.3 & 2.073 \\
Scrub Surgical Tech 2 & 0.32 & 0.32 & 1.3 & 1.772 \\
$\quad$ Nurse & &
\end{tabular}

It was mentioned by Cong Wang [12] that boundary conditions have a crucial role in generating a reliable simulation result. F. Memarzadeh et al. [13] recommended the range of temperature in ORs between $16.67^{\circ} \mathrm{C}$ and $26.67^{\circ} \mathrm{C}$ and using a unidirectional airflow supplied from diffuser. Therefore, this study utilized an inlet temperature in the range of $16^{\circ} \mathrm{C}$ to $20^{\circ} \mathrm{C}$ with one degree increase. Three air velocities of $0.2,0.25$ and $0.35 \mathrm{~m} / \mathrm{s}$ were used to study the influence of air velocity in analysing thermal comfort. The selected air velocities were in an acceptable range based on the study of Gaever et al. [14]. Draughts' discomfort may exist in surgical site if the study utilizes an air velocity beyond $0.45 \mathrm{~m} / \mathrm{s}$. Besides that, high infection rates can occur in surgical site when 
using LAF ventilation at $0.45 \mathrm{~m} / \mathrm{s}$ and above of air velocity as studied by [13] and [15]. Thus, this study used vertical LAF system at the mentioned air velocity values. Moreover, the relative humidity (RH) for this study was maintained at $55 \%$ which is within the recommended range by J. M. Walker et al. [16] and Balaras et al. [17]. The ACH was maintained at 20 as referred to the standard. This study was assumed to be in a steady-state condition [12] and Table 2 summarizes the numerical boundary and thermal values.

Table 2: Numerical boundary conditions and thermal values

\begin{tabular}{|c|c|c|}
\hline No. & Variables & Boundary conditions \\
\hline 1 & Surgeon & \\
\hline 2 & Scrub surgical tech & metabolic rate $=1.6$ met, clothing insulation $=0.86$ \\
\hline 3 & Nurse anaesthetist & metabolic rate $=1.4$ met, clothing insulation $=0.70$ \\
\hline 4 & Circulating tech & metabolic rate $=1.6$ met, clothing insulation $=0.70$ \\
\hline 5 & Nurse & metabolic rate $=1.6$ met, clothing insulation $=0.75$ \\
\hline 6 & Anaesthetist machine & Heat dissipation $150 \mathrm{~W}$ \\
\hline 7 & Floor & \\
\hline 8 & Ceiling & Adighatio \\
\hline 9 & Walls & Acrabatic \\
\hline 10 & Operation table & \\
\hline 11 & Surgical light & Heat dissipation capacity $100 \mathrm{~W}$ \\
\hline 12 & Inlet & Velocity-Inlet, Air velocity $=0.2,0.25,0.35 \mathrm{~m} / \mathrm{s}$, Temperature $=16-20^{\circ} \mathrm{C}$ \\
\hline 13 & Outlet & Pressure-Outlet \\
\hline
\end{tabular}

* Note: Metabolic rate $1 \mathrm{met}=58 \mathrm{~W} / \mathrm{m}^{2}$ and no slip condition for all elements

\subsection{Evaluation of PMV and PPD}

Previously, most of PMV and PPD evaluations used manual calculation to measure the comfort level. As a result, it led to a non-user-friendly approach due to its complexity. Hence, this study used a simpler interface known as CBE Thermal Comfort Tool invented by the research team from the Center for the Built Environment, University of California, Berkeley [18]. The tool requires an input value from each parameter under the environmental and individual factors. The parameters involved are air temperature, mean radiant temperature, air velocity, humidity, clothing insulation and metabolic rate. The input parameters values are illustrated in Table 2 and under the description of numerical modelling. This tool obeys two international standards which are the European and ASHRAE standards. Upon calculation, the value of PMV and PPD can be observed easily on the psychometric chart. Moreover, the recommended range values of PMV and PPD are $-0.5<$ PMV $<0.5$ while PPD is suggested to be $<10 \%$.

\subsection{RESULTS AND DISCUSSION \\ 3.1 Air velocity distribution}

The velocity distribution contour for Design 1 and 2 was plotted at xy plane being cut at a value of $-3 \mathrm{~m}$ as shown in Figs. 3 and 4. Each figure shows the utilization of different air velocities at $0.2,0.25$ and $0.35 \mathrm{~m} / \mathrm{s}$ with five different operative temperatures for each velocity. The airflow pattern obtained from the simulation analysis was a downward unidirectional flow which greatly depended on the inlet diffuser and outlet exhaust vent position. It was observed that the air was supplied from the inlet diffuser located at the center of the ceiling and the air returned through the exhaust vent positioned at low level (Design 1) and high level (Design 2). In spite of this observation, the airflow constantly produced a vertical down-flow air pattern for both designs which contributed to the utilization of LAF ventilation system. The assigned range value of air velocity distribution contour in the operation rooms was between 0 and $0.4 \mathrm{~m} / \mathrm{s}$ in order to monitor the behaviour of the air movement and speed. It was found that the greater the air velocity, the more aggressive the flow of the air inside the surgical site which gave influence in providing comfort to the occupants. These results are considerable because both designs are not showing an aggressively high displacement of the maximum velocity throughout the entire simulated operation room models. In addition, the results are still below the suggested velocity value which must be not greater than $0.45 \mathrm{~m} / \mathrm{s}[13-15]$. 


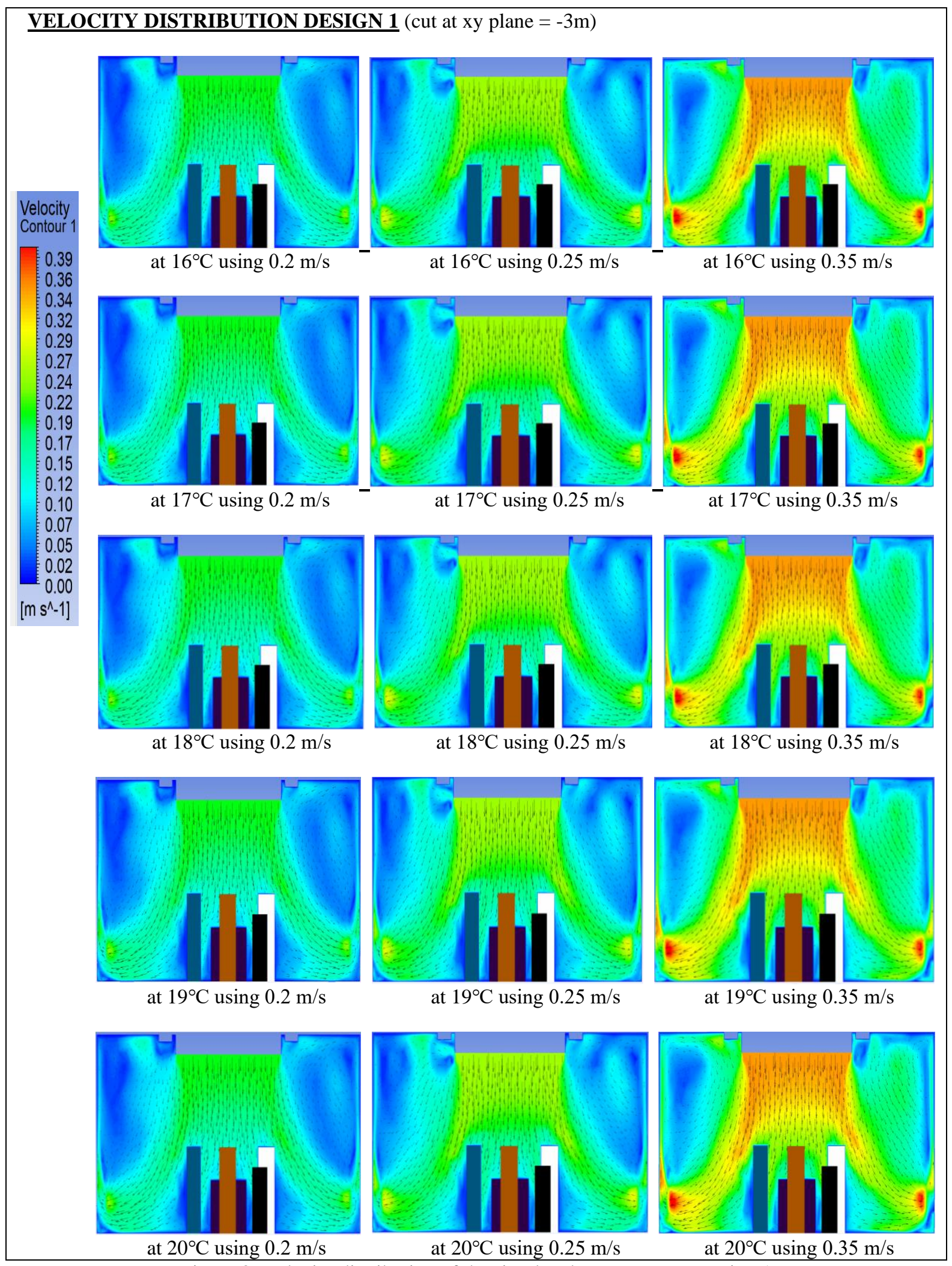

Figure 3: Velocity distribution of the simulated surgery room Design 1 


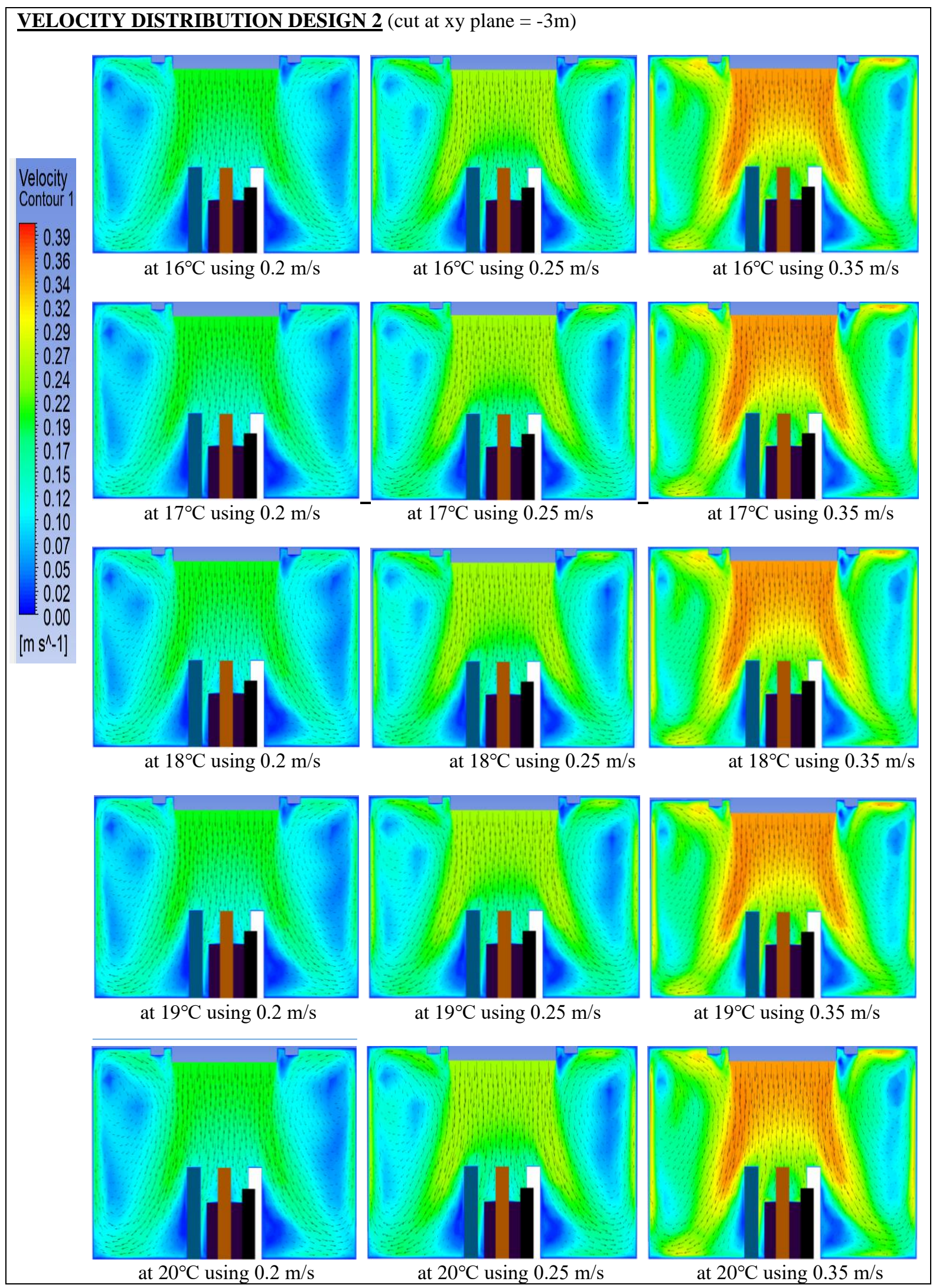

Figure 4: Velocity distribution of the simulated surgery room Design 2 
From the simulation results, it was observed that a circulation occurred at the top corner of the OR for each assigned value of velocity and temperature. These results are validated through the results of previous studies by several authors in their journals [19], [8], [12], [20-21] which happened to experience a circulation within their simulated models when utilizing a vertical unidirectional LAF ventilation system.

\subsection{Temperature distribution}

The contour of the temperature distribution for Design 1 and Design 2 is illustrated in Figs. 5 and 6. Both of the OR designs were analysed from the xz plane at a value of $0.7 \mathrm{~m}$ above the floor. Each figure shows the influence of air velocity in controlling the distribution of the temperature within the OR model. Similar to the velocity distribution, each figure shows the utilization of different air velocities at $0.2,0.25$ and $0.35 \mathrm{~m} / \mathrm{s}$ with five different operative temperatures for each velocity. From the simulation results, it was observed that the air velocity used completely gave an impact on the temperature distribution within the OR. The highest temperature in the simulated model was set to be at $25^{\circ} \mathrm{C}$ while the minimum temperature value was $16^{\circ} \mathrm{C}$. The range of these temperatures used obeys the suggested value recommended by F. Memarzadeh et al. [13]. It was observed from the temperature distribution figures that the displacement of the temperature for surgical workers was reduced with the increase of air velocity. Hypothetically, this observation revealed that the lesser the displacement of temperature distribution, the more comfortable the surgical workers would feel when working under the measured temperature. 


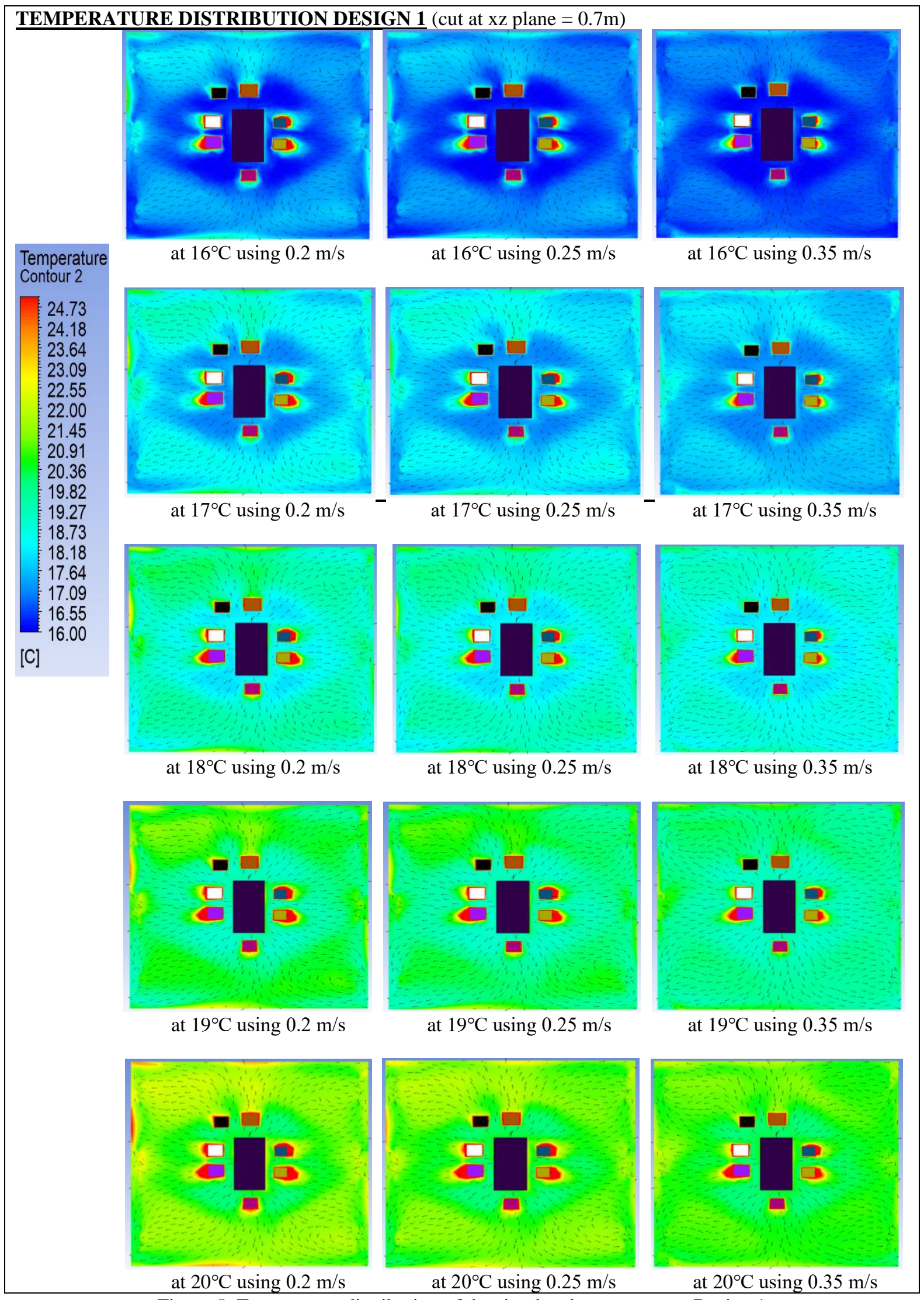

Figure 5: Temperature distribution of the simulated surgery room Design 1 


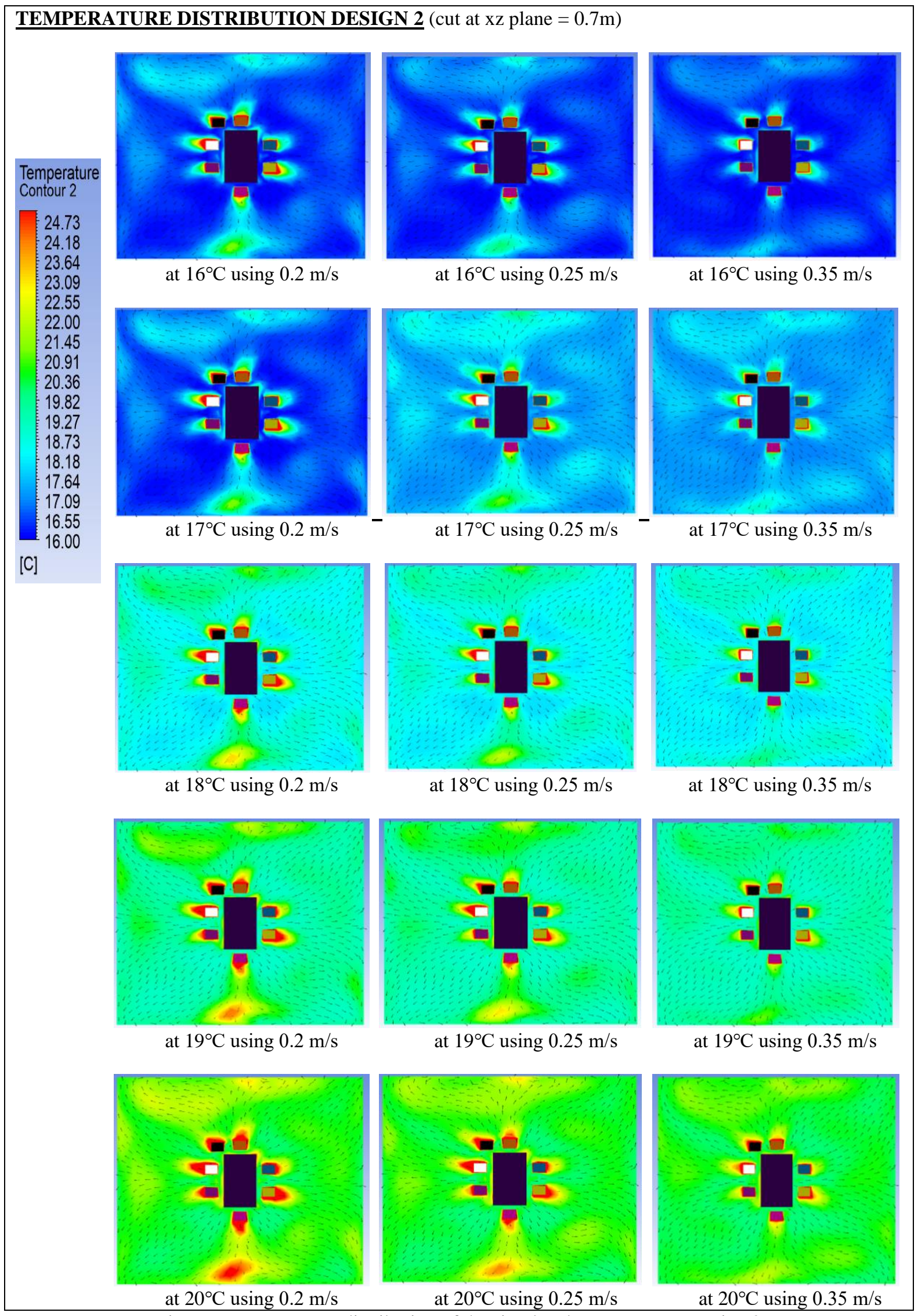

Figure 6: Temperature distribution of the simulated surgery room Design 2 


\subsection{PMV and PPD Data}

\subsubsection{PMV}

Figs. 7, 8 and 9 below show the results of PMV values obtained from CBE Thermal Comfort Tool to measure the comfort level achieved by each of the surgical workers. It was observed that nurse anaesthetist had the highest PMV value while surgeon and scrub surgical tech had the lowest PMV value throughout the 5 measured temperatures and 3 different air velocities. The PMV values for other surgical workers were between the surgeon, scrub tech and nurse anaesthetist. Furthermore, by neglecting the bar chart, it was observed that the graph of the PMV approach linearly increased as the measured temperature increased.

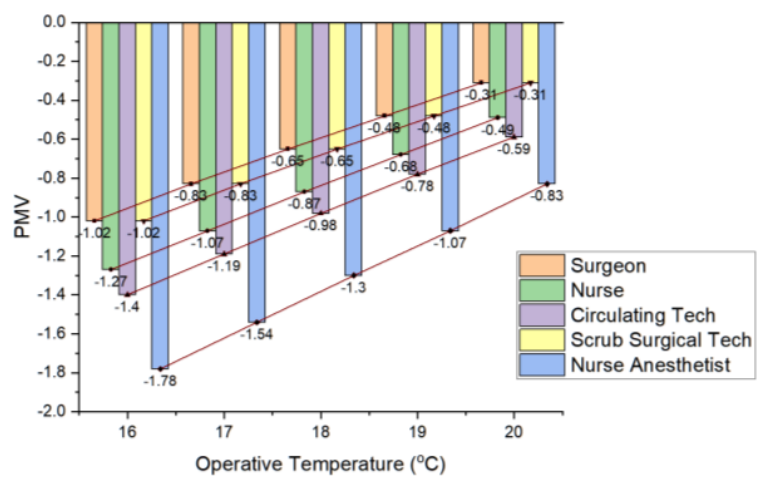

Figure 7: PMV value of surgical staffs at $0.2 \mathrm{~m} / \mathrm{s}$

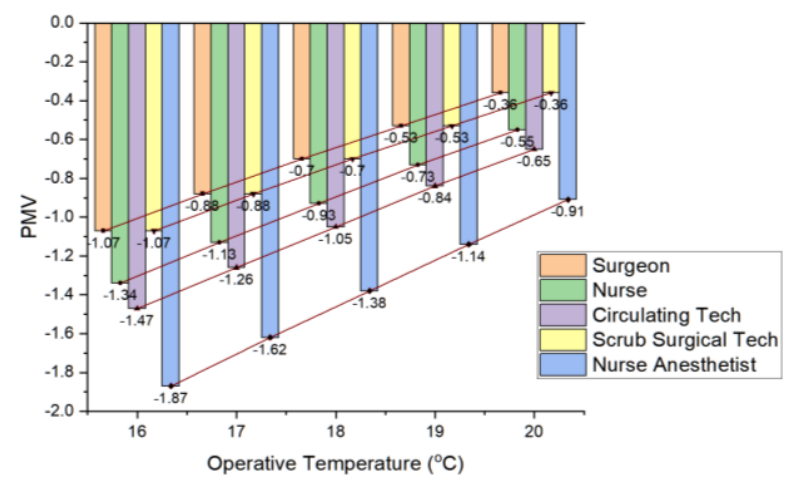

Figure 8: PMV value of surgical staffs at $0.25 \mathrm{~m} / \mathrm{s}$

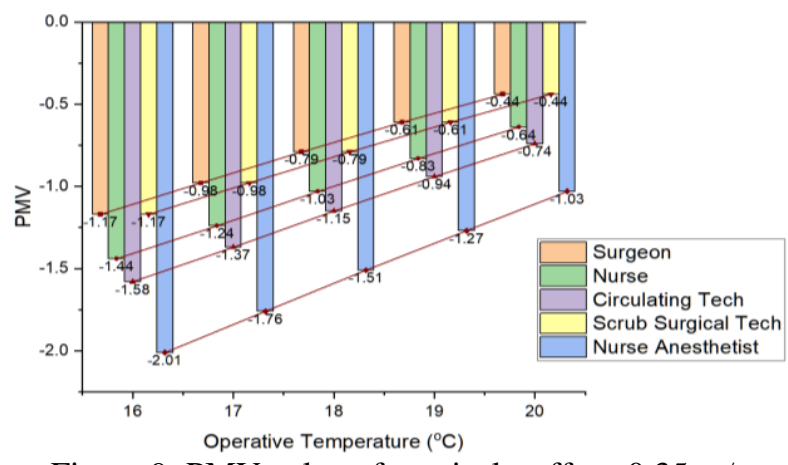

Figure 9: PMV value of surgical staffs at $0.35 \mathrm{~m} / \mathrm{s}$

The comfort level of the surgical workers was measured using the standard PMV index scale guideline by ISO 7730 [22] as in Table 3. According to [23], the PMV value should be between $-0.5 \leq \mathrm{PMV} \leq+0.5$. In relation to the problem statement, there were complaints from surgical workers who experienced thermal discomfort even when the operation room followed the standard thermal guidelines. Therefore, the recommended range of PMV value that should be met in this study was between $-1 \leq \mathrm{PMV} \leq+1$ where this range was acceptable to provide comfort for the occupants [24]. Next, the obtained PMV results revealed that most of the surgical workers experienced a near cool sensation. It was due to several factors which influenced their comfortability such as metabolic rate and clothing insulation. In accordance to the gathered thermal parameters from previous studies, nurse anaesthetist had the lowest metabolic rate and clothing insulation. It is because nurse anaesthetist does not need to juggle around the operation room compared to other workers as he or she spends most of the time sitting in front of the anaesthetist machine. It is also set that nurse anaesthetist wears hospital scrubs which include only underwear, shoes and socks compared to the surgeon who wears gown, gloves and galoshes as well as other workers who need to wear hospital scrubs and warm-up jacket. Additionally, nurse anaesthetist is directly exposed to the heat produced by the anaesthetist machine and surgical lights that may contribute to the balance of coolness that he or she experiences. 
Table 3: PMV index scale [22]

\begin{tabular}{cc}
\hline Value & Thermal Sense \\
\hline-3 & cold \\
-2 & cool \\
-1 & slightly cool \\
0 & neutral \\
+1 & slightly warm \\
+2 & warm \\
+3 & hot \\
\hline
\end{tabular}

\subsubsection{PPD}

The PPD has a strong link with the value obtained in PMV approach. If the value obtained in PMV is in neutral scale, the PPD will have a value below $10 \%$ of temperature dissatisfaction. Similar to the PMV, PPD technique also predicts the percentage of individual that feels thermally dissatisfied with the environment temperature. Referring to the PPD results obtained in Figs. 10, 11 and 12, the nurse anaesthetist had the highest dissatisfaction percentage with the surrounding temperature throughout the 5 measured temperatures and 3 different air velocities. In this study, it was recommended that the PPD value should be less than < $20 \%$ in order to obtain thermal comfort conditions. According to the graphs below, the behaviour of the graph linearly decreased towards zero value. However, the relationship between PMV and PPD showed that even when the PMV value was zero, there was still a percentage of people that felt dissatisfied with the surrounding temperature. It was observed that majority of the surgical workers felt dissatisfied when utilizing the operative temperature of below $19^{\circ} \mathrm{C}$.

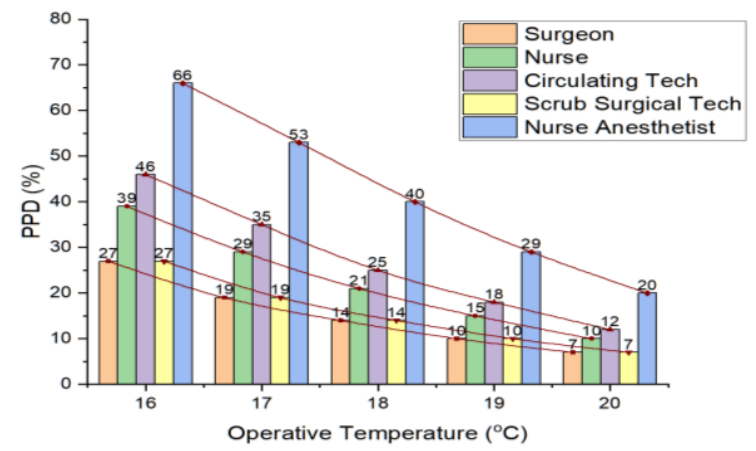

Figure 10: PPD value of surgical staffs at $0.2 \mathrm{~m} / \mathrm{s}$

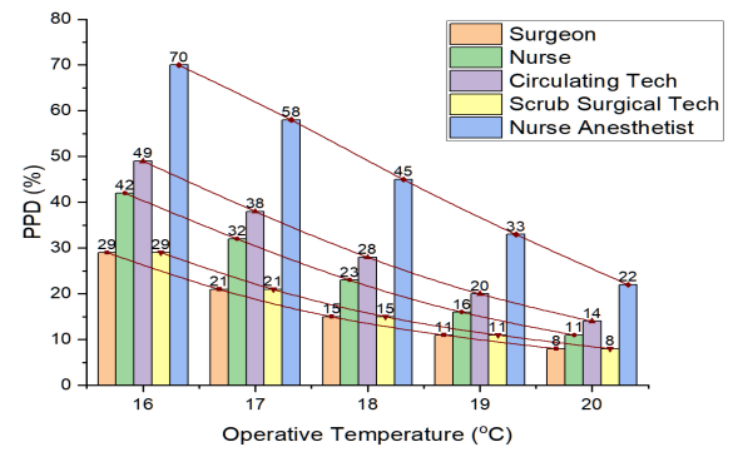

Figure 11: PPD value of surgical staffs at $0.25 \mathrm{~m} / \mathrm{s}$

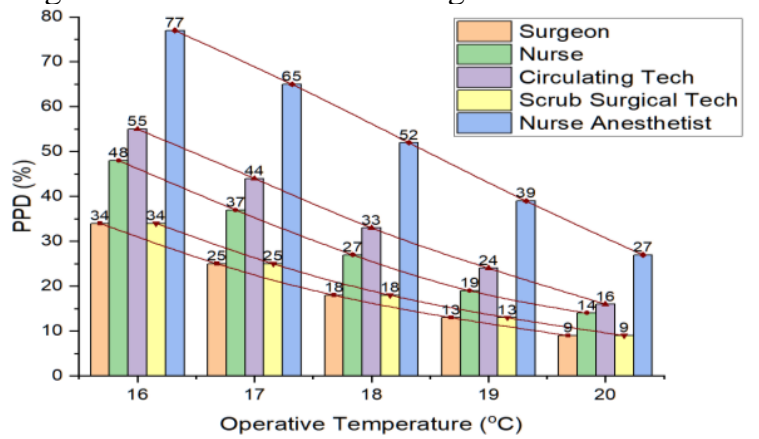

Figure 12: PPD value of surgical staffs at $0.35 \mathrm{~m} / \mathrm{s}$

\subsection{Comparison of simulated designs}

The CFD analysis of simulated designs was compared in terms of velocity distribution, airflow pattern, position of outlet exhaust vent and temperature distribution. Figs. 13 and 14 show the comparison of velocity distribution between Design 1 and Design 2 using identical operative temperature of $19{ }^{\circ} \mathrm{C}$ and air velocity of 0.2 $\mathrm{m} / \mathrm{s}$. It was observed that a circulation aggressively occurred at the top left and right corner of Design 1 . In Design 2 , the air circulation was assumed to be exhausted much easier due to the position of the exhaust vent. In terms of infection, Design 2 provided a safer environment due to the minimal air circulation in the surgical site. It is because the trapped air inside the operation room may contain bacteria or harmful microorganism which could threaten the patient during the surgery. Hypothetically, high circulating air inside the operation room may increase the chance of the patient to obtain undesired infection. 


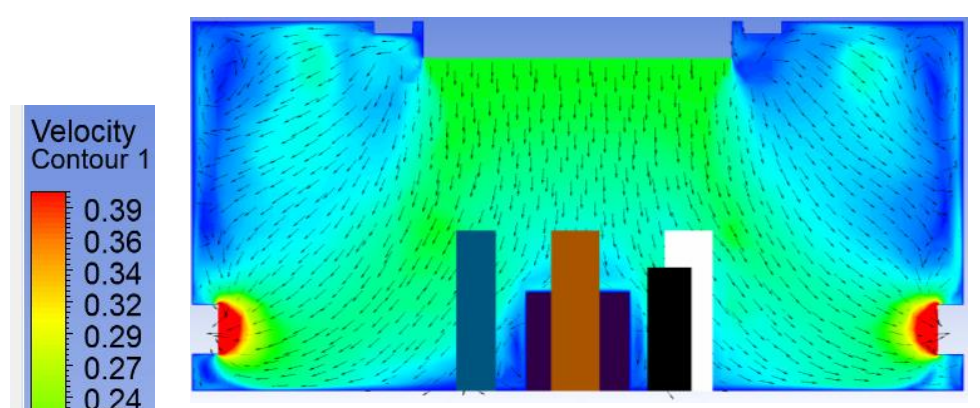

Figure 13: Velocity distribution of Design 1

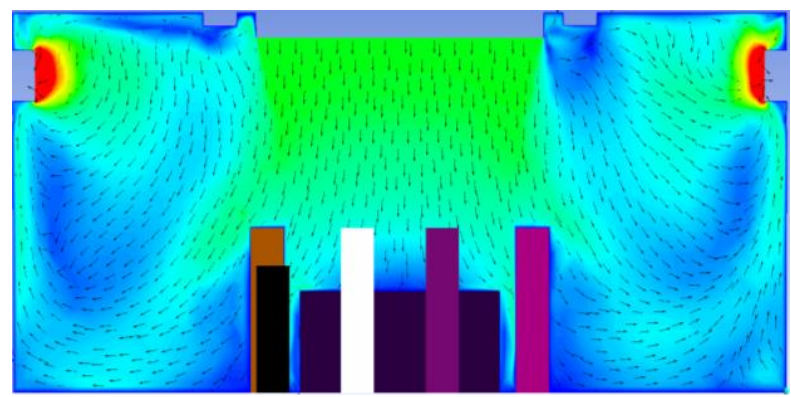

Figure 14: Velocity distribution of Design 2

Besides the airflow pattern and velocity distribution, the simulated designs were also compared in terms of temperature distribution. For temperature variable, it has a great relationship in monitoring the comfort level of the surgical workers. The red contour around the simplified human block models in Figs. 15 and 16 indicated the heat experienced by the surgical workers. The more aggressive the colour contour, the more uncomfortable the surgical workers feel. However, the results of this temperature distribution were set in the range of $16^{\circ} \mathrm{C}$ to $25^{\circ} \mathrm{C}$ which means that they may be considered in a comfortable or cool state. In previous studies, the suggested temperature for the surgical workers was between 20 and $22^{\circ} \mathrm{C}$ [25-26]. Hence, the temperature below the suggested temperature may be categorized as slightly cool or cool. By comparing the temperature distribution, the position of the exhaust vent at a high level is better in reducing the red contour displacement.

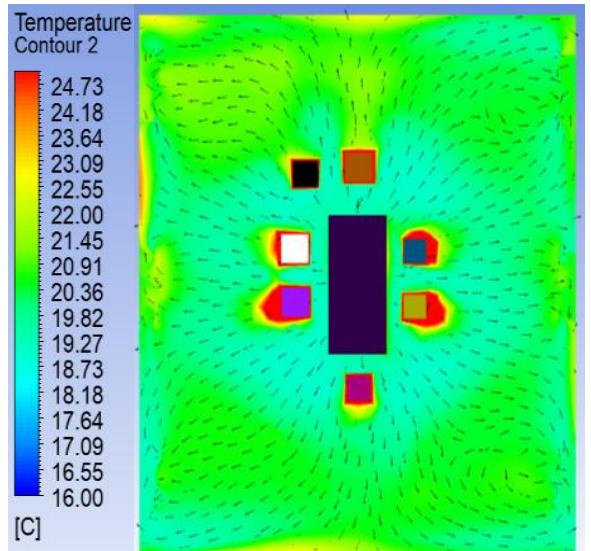

Figure 15: Temperature distribution of Design 1

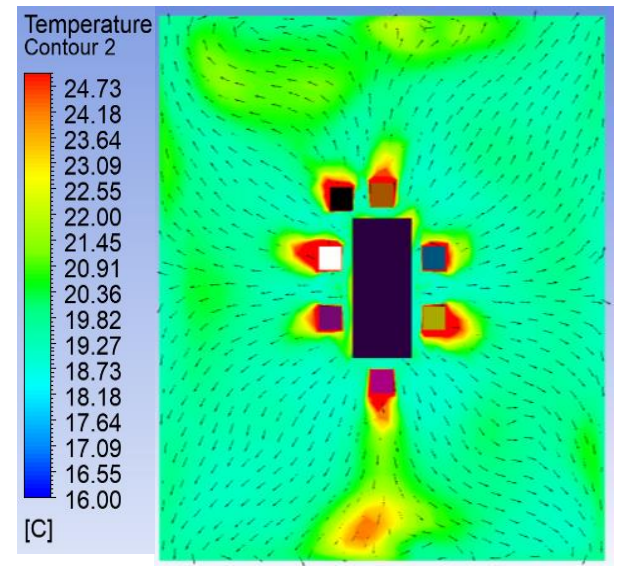

Figure 16: Temperature distribution of Design 2

\subsection{CONCLUSION}

In a nutshell, this study focuses on the analysis of thermal comfort in operation room. The constructed models were simulated in 5 different temperatures of $16^{\circ} \mathrm{C}$ to $20^{\circ} \mathrm{C}$ and 3 different air velocities of $0.2,0.25$ and $0.35 \mathrm{~m} / \mathrm{s}$. The results show that the environmental and individual factors give a great influence towards thermal comfort. Generally, when observing the PMV and PPD graphs, the standard thermal indexes guidelines can still be achieved even though the measured temperature increases to $25^{\circ} \mathrm{C}$. Most of the surgical workers have thermal sensation from slightly cool to neutral and from cool to slightly cool. The arrangement of the devices in the operation room is also vital role because these devices contribute towards heat into the space. In this study, the configuration is simplified and the measurements are taken and simulated. As a result, it shows that anaesthetist machine and surgical lights give a great effect towards temperature distribution. Assuming a real operation room is built, the 
complexity of the device arrangement may hit above great in analysing thermal comfort. Additionally, the position of the exhaust vent plays an important role in resulting airflow pattern. It can be concluded that the operation room of Design 2, which has a high-level exhaust vent position, delivers better and safe environment due to less air circulation produced. As a consequence, the risk of patient in getting infection is reduced.

\section{ACKNOWLEDGEMENT}

The authors would like to express their gratitude to Universiti Teknologi MARA for the research support under MyRA Grant - File No. 600-RMC/MyRA 5/3/LESTARI (050/2020).

\section{REFERENCES}

[1] Ding Lai Chet, "Case Study of Air Distribution of the Hospital Operating Room in Malaysia," 2012.

[2] I. Nastase, C. Croitoru, A. Vartires, and L. Tataranu, "Indoor Environmental Quality in Operating Rooms: An European Standards Review with Regard to Romanian Guidelines," Energy Procedia, vol. 85, pp. 375-382, 2016, doi: 10.1016/j.egypro.2015.12.264.

[3] Radostina A. Angelova and Rositsa Velichkova, "Thermophysiological Comfort of Surgeons and Patient in an Operating Room Based on PMV-PPD and PHS Indexes," Applied Sciences (Switzerland), vol. 10, no. 20, pp. 1-22, March 2020, doi: 10.3390/app10207030.

[4] Guan Heng Yeoh and Kwok Kit Yuen, "Computational Fluid Dynamics in Fire Engineering (Theory, Modelling and Practice)”, Elsevier, 2009, doi: 10.1016/b978-0-7506-8589-4.00002-8.

[5] F. Moukalled, L. Mangani, and M. Darwish, Fluid Mechanics and Its Applications The Finite Volume Method in Computational Fluid Dynamics, Springer International Publishing Switzerland, vol. 113, 2016, doi: 10.1007/978-3-319-16874-6.

[6] M. H. Zawawi, A. Saleha, A. Salwa, N.H. Hassan, N.M. Zahari, M.Z. Ramli and Z.C. Muda, “A Review: Fundamentals of computational fluid dynamics (CFD)," AIP Conference Proceedings, vol. 2030, November 2018, doi: 10.1063/1.5066893.

[7] ASHRAE Standard 55, "Thermal Environmental Conditions for Human Occupancy", 2004.

[8] C. Liu, G. Zhou, and H. Li, "Analysis of Thermal Environment in a Hospital Operating Room, "Procedia Engineering, vol. 121, pp. 735-742, 2015, doi: 10.1016/j.proeng.2015.09.021.

[9] M. Prek, "Thermodynamic analysis of human heat and mass transfer and their impact on thermal comfort," International Journal of Heat and Mass Transfer, vol. 48, no. 3-4, pp. 731-739, January 2005, doi: 10.1016/j.ijheatmasstransfer.2004.09.006.

[10] Y. H. Yau and L. C. Ding, "A case study on the air distribution in an operating room at Sarawak General Hospital Heart Centre (SGHHC) in Malaysia," Indoor and Built Environment, vol. 23, no. 8, pp. 11291141, December 2014, doi: 10.1177/1420326X13499359.

[11] Y. Zhang and Y. Ji, "Human Environmental Heat Transfer Simulation with CFD: The Advances and Challenges," Eleventh International IBPSA Conference, July 2009.

[12] C. Wang, "Ventilation Performance in Operating Rooms: A Numerical Assessment," KTH School of ABE, Sweden, 2019.

[13] F. Memarzadeh, P. E. Andrew, and P. Manning, "Comparison of Operating Room Ventilation Systems in the Protection of the Surgical Site", ASHRAE Transactions, January 2004.

[14] R. van Gaever, V. A. Jacobs, M. Diltoer, L. Peeters, and S. Vanlanduit, "Thermal comfort of the surgical staff in the operating room," Building and Environment, vol. 81, pp. 37-41, 2014, doi: 10.1016/j.buildenv.2014.05.036.

[15] T. Ahl, N. Dalen, H. Jörbeck, and J. Hobom, "Air contamination during hip and knee arthroplasties: Horizontal laminar flow randomized vs. Conventional ventilation," Acta Orthopaedica, vol. 66, no. 1, pp. 17-20, 1995, doi: 10.3109/17453679508994632.

[16] ASHRAE Technical Committee 9.6, Healthcare Facilities, "Humidity Control Events in Perioperative Care Areas", 2019.

[17] C. A. Balaras, E. Dascalaki, and A. Gaglia, "HVAC and indoor thermal conditions in hospital operating rooms," Energy and Buildings, vol. 39, no. 4, pp. 454-470, April 2007, doi: 10.1016/j.enbuild.2006.09.004.

[18] F. Tartarini, S. Schiavon, T. Cheung, and T. Hoyt, "CBE Thermal Comfort Tool: Online tool for thermal comfort calculations and visualizations," SoftwareX, vol. 12, July 2020, doi: 10.1016/j.softx.2020.100563.

[19] H. Ufat, O. Kaynakli, N. Yamankaradeniz, and R. Yamankaradeniz, "Three-dimensional air distribution analysis of different outflow typed operating rooms at different inlet velocities and room temperatures," Advances in Mechanical Engineering, vol. 9, no. 7, July 2017, doi: 10.1177/1687814017707414. 
[20] T. T. Chow, Z. Lin, and W. Bai, "The integrated effect of medical lamp position and diffuser discharge velocity on ultra-clean ventilation performance in an operating theatre," Indoor and Built Environment, vol. 15, no. 4, pp. 315-331, August 2006, doi: 10.1177/1420326X06067802.

[21] T. T. Chow and X. Y. Yang, "Performance of ventilation system in a non-standard operating room," Building and Environment, vol. 38, no. 12, pp. 1401-1411, 2003, doi: 10.1016/S0360-1323(03)00155-0.

[22] EN ISO 7730, "Ergonomics of the Thermal Environment - Analytical Determination and Interpretation of Thermal Comfort Using Calculation of the PMV and PPD Indices and Local Thermal Comfort Criteria", 2005.

[23] ASHRAE Handbook, "HVAC Application: Healthcare Facilities", 2007.

[24] M. Zwolińska and A. Bogdan, "Thermal sensations of surgeons during work in surgical gowns," International Journal of Occupational Safety and Ergonomics, vol. 19, no. 3, pp. 443-453, 2013, doi: 10.1080/10803548.2013.11077000.

[25] Harvey R. Bernard, "The Design and Utilization of Operating Theatres", 1984.

[26] B. D. P Wyon and M. Lidwell, "Thermal comfort during surgical operations," J. Hyg., Camb, vol. 66, pp. 229-248, 2021, doi: 10.1017/S0022172400041103. 